\title{
Estimation of the potential of an anaerobic thermophilic oil-degrading bacterium as a candidate for MEOR
}

\author{
Isty Adhitya Purwasena • Yuichi Sugai • \\ Kyuro Sasaki
}

Received: 14 June 2013/Accepted: 9 December 2013/Published online: 20 December 2013

(C) The Author(s) 2013. This article is published with open access at Springerlink.com

\begin{abstract}
We investigated the decrease in oil viscosity caused by the biodegradation of crude oil by a bacterium (AR80) isolated from an oil reservoir, and estimated the potential for this bacterium for use in microbial enhanced oil recovery (MEOR). AR80 degraded long-chain $n$ alkanes preferentially, and anaerobically increased the ratio between the short-chain and long-chain $n$-alkane concentrations in the crude oil. The long-chain $n$-alkane metabolism by AR80 decreased the oil viscosity. AR80 grew well in a reservoir of brine supplemented with yeast extract, and decreased the oil viscosity to approximately $60 \%$ of its original value. Adding a small amount of yeast extract $(0.05 \mathrm{~g} / \mathrm{L})$ was necessary to stimulate the AR80 activity. MEOR can, therefore, be achieved using AR80 without incurring excessive costs. AR80 can grow at temperatures up to $80^{\circ} \mathrm{C}$ and grows well at between 50 and $70^{\circ} \mathrm{C}$. AR80 can grow at a salinity of up to $90 \mathrm{~g} / \mathrm{L}$ and grows well at a salinity of $<30 \mathrm{~g} / \mathrm{L}$. The AR80 activity was not affected very much by high pressures (such as 6.0 MPa). Core flooding experiments were performed by injecting AR80 (in brine supplemented with yeast extract) into Berea sandstone cores. Gas chromatography analysis of the effluent oil suggested that long-chain $n$-alkanes in the residual oil were preferentially degraded by the AR 80 in the porous rocks. The core flooding experiments showed that the
\end{abstract}

\footnotetext{
I. A. Purwasena

School of Life Science and Technology, Bandung Institute of

Technology, Ganesha 10, Bandung 40132, West Java, Indonesia

Y. Sugai $(\varangle) \cdot$ K. Sasaki

Department of Earth Resources Engineering, Faculty of

Engineering, Kyushu University, 744 Motooka, Nishi-ku,

Fukuoka 819-0395, Japan

e-mail: sugai@mine.kyushu-u.ac.jp
}

AR80 activity in the porous rocks caused the oil recovery to be enhanced, so AR80 could be a suitable candidate for MEOR.

Keywords Microbial enhanced oil recovery - Oildegrading bacteria . Oil viscosity - Yeast extract . Reservoir conditions · Core flooding

\section{Introduction}

Microbial enhanced oil recovery (MEOR) is well known as both an economically feasible and an environmentally friendly enhanced oil recovery technique that uses biotechnology or microbial biological activity. MEOR generally involves injecting effective microorganisms and nutrients into oil reservoirs where they are then incubated. Decreasing the viscosity of crude oil through biodegradation and/or bioproducts, such as surfactants and polymers, leads to improved oil recovery.

Molasses, which is produced as a byproduct of sugar refining, has been used in many MEOR field trials as a nutrient for the microorganisms used (Bass and LappinScott 1997). Molasses is cheap and contains nutrients, such as sucrose, minerals, organic compounds, and vitamins (Hanaa et al. 2011). However, the cost of molasses has increased progressively over the last few decades because of its extensive use as a raw material for bioethanol production. For example, Chinese molasses rose in price from US $\$ 40 /$ ton in 2000 to US\$200/ton in 2007 (Fujiwara et al. 2008). The cost of transporting molasses is high if there are no sugar refinery plants near the oilfield being treated. A sterilization facility is necessary so that molasses, which often contains various bacteria, can be sterilized before use in MEOR. The activity of the injected microorganism(s) may

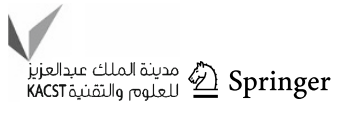


be hindered by the growth of unwanted bacteria in an oil reservoir because molasses is rich in nutrients that can stimulate the growth of a wide range of bacteria. It is, therefore, predicted that using molasses during MEOR will become unattractive in the near future.

Using microorganisms that specifically consume crude oil as their sole carbon source in MEOR processes could be a way of avoiding the need to add molasses. These microorganisms can break long-chain hydrocarbons in crude oil into shorter chains, resulting in a decrease in the oil viscosity and improved oil mobility. Lazar et al. (1999) suggested that microorganisms could be used to decrease the proportion of long-chain $n$-alkanes present in biotechnological processes that involve waxy crude oil, to improve the recovery of the oil. Yijiang et al. (1999) described a successful MEOR field trial using oil-degrading bacteria without the injection of any nutrients. They concluded that the oil recovery was enhanced because of a decrease in the oil viscosity caused by the injected bacteria. However, a number of unknown bacterial strains had been injected into the reservoir in that study, and it is unclear which bacteria had caused the decrease in viscosity, so the reproducibility of the effects was left as an open question. Later, single species of hydrocarbon-degrading bacteria, including Bacillus spp. (Wankui et al. 2006), Brevibacillus spp. (Wang et al. 2008), Pseudomonas spp. (Sadeghazad and Ghaemi 2003), and Acinetobacter spp. (Kotlar et al. 2007), were used in MEOR. However, all of these species are aerobic and/or facultative anaerobic bacteria, and need oxygen to degrade the hydrocarbons. To achieve this, an aerated nutrient solution was, therefore, injected into the oil reservoirs in the MEOR field trials using aerobic bacteria (Youssef et al. 2009). Using this method, the growth of the bacteria was limited to near the injection wells because the dissolved oxygen was entirely consumed there. This resulted in the oil viscosity only decreasing near the injection wells, so the enhancement in the oil recovery was not particularly great. Using anaerobic hydrocarbondegrading bacteria in MEOR would, therefore, be a way of improving the MEOR performance.

Dong-Hui et al. (2008) described a novel anaerobic paraffin-degrading Gordonia sp. bacterium and suggested that this bacterium had the potential for being used in MEOR. However, the enhanced oil recovery potential of the bacterium was not demonstrated in their core flooding experiments. This bacterium may not be practically used for MEOR because it can only live at below $40{ }^{\circ} \mathrm{C}$, which is lower than the temperature in many oil reservoirs. There have been few reports of thermophilic anaerobic hydrocarbon-degrading bacteria that could be practically used for MEOR so far. We are investigating the use of thermophilic anaerobic hydrocarbon-degrading bacteria for MEOR. We have successfully isolated an anaerobic bacterium, and identified it as a strain belonging to the Petrotoga sp., from an oil reservoir in Japan (Isty et al. 2014). Although six species of Petrotoga have been isolated from several oilfields so far (Miranda-Tello et al. 2007), none of them has been found to degrade hydrocarbons or be candidates for use in MEOR. Our isolate (named AR80) can grow at $\geq 50{ }^{\circ} \mathrm{C}$ in a culture medium containing crude oil as the sole carbon source. This species may, therefore, anaerobically degrade hydrocarbons and decrease the viscosity of oil at high temperatures. If this is the case it could be a candidate for use in MEOR.

The purpose of the study presented here was to demonstrate the potential use of AR80 for MEOR using incubation experiments and core flooding experiments, including typical reservoir conditions. In particular, we investigated the influences of several incubation conditions, both controllable and uncontrollable during MEOR, on the AR80 activity. The types of substrates and their concentrations (which are controllable conditions), and reservoir conditions, such as temperature, salinity, and pressure (which are uncontrollable conditions), were studied. The results of these investigations allow us to propose an effective method for using AR80 in MEOR and to describe the reservoir conditions under which AR80 can be used.

\section{Experimental}

Bacterial strain and culture medium preparation

An AR80 cell is rod-shaped, $0.25-0.75 \mu \mathrm{m}$ wide, and 2.5-7.0 $\mu \mathrm{m}$ long, and it has a characteristic outer sheathlike structure and polar flagella, as shown in Fig. 1. The motility of AR80 cells can be expected to allow them to penetrate the micropores in reservoir rocks.

Pure culture experiments were performed using AR80 to estimate its ability to decrease oil viscosity. A culture medium consisting of natural brine and crude oil was used. The natural brine and the crude oil had both been collected from an oil-producing well in the Yabase oilfield, Akita, Japan. Table 1 shows the brine composition used in the study. The salinity of the brine was approximately $1.0 \%$ and the API gravity of the crude oil was approximately $33^{\circ}$.

Filter-sterilized brine $(50 \mathrm{~mL})$ was put into autoclaved serum bottles $(100 \mathrm{~mL})$, and autoclaved crude oil $(1.0 \mathrm{~mL})$ was added to act as the sole carbon source. Each bottle was sealed with a butyl rubber cap and an aluminum crimp. The headspace was replaced with $10 \% \mathrm{CO}_{2}$ in $\mathrm{N}_{2}$ in all of the experiments because AR80 had been isolated from natural brine that had been incubated in the presence of $\mathrm{CO}_{2}$ (Isty 


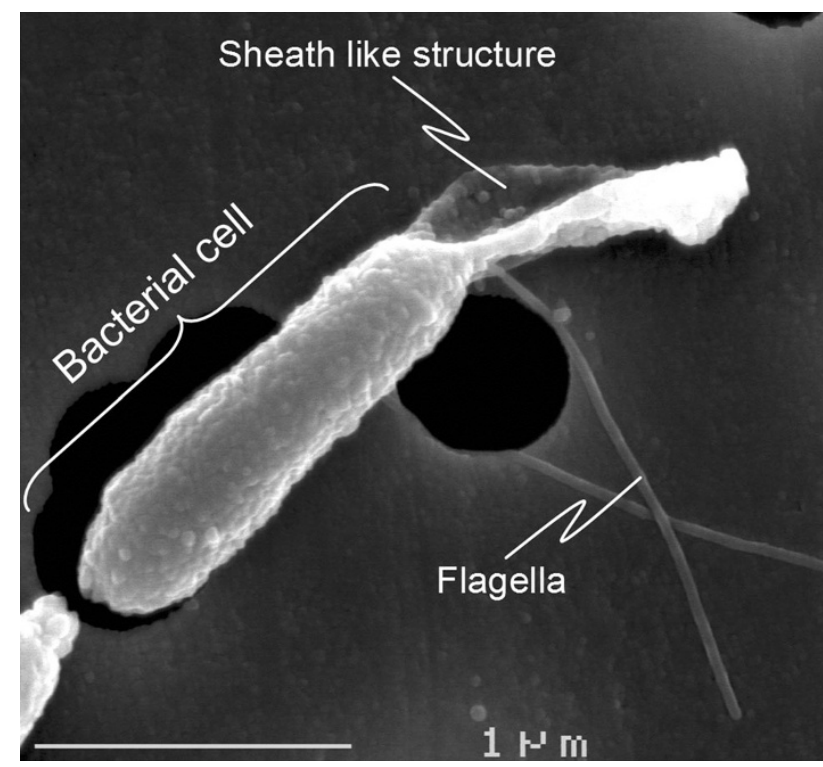

Fig. 1 Scanning electron microscopy image of the AR80 bacterium

Table 1 Compositions of the brine used for the culture medium

\begin{tabular}{ll}
\hline Component & $\begin{array}{l}\text { Concentration } \\
(\mathrm{mg} / \mathrm{l})\end{array}$ \\
\hline $\mathrm{Na}^{+}$ & 3,075 \\
$\mathrm{~K}^{+}$ & 30 \\
$\mathrm{Ca}^{2+}$ & 5 \\
$\mathrm{Mg}^{2+}$ & 3 \\
$\mathrm{Cl}^{-}$ & 2,500 \\
$\mathrm{I}^{-}$ & 1.5 \\
$\mathrm{NH}_{4}{ }^{+}$ & 15 \\
$\mathrm{HBO}_{2}{ }^{2-}$ & 250 \\
$\mathrm{~T}_{-}-\mathrm{Fe}$ & 2 \\
$\mathrm{HCO}_{3}{ }^{-}$ & 4,000 \\
Lactic acid & $<0.1$ \\
Formic acid & 2.2 \\
Acetic acid & 4.3 \\
Propionic acid & $<0.1$ \\
\hline
\end{tabular}

et al. 2014). An AR80 cell suspension ( $5 \mathrm{~mL}$ ) was inoculated into each bottle containing culture medium and the bottles were incubated at $50{ }^{\circ} \mathrm{C}$. The initial AR80 concentration in the culture medium in each bottle was $1.0 \times 10^{6}$ cells $/ \mathrm{mL}$. Several bottles with identical conditions were prepared for each experiment and an un-inoculated control was also prepared and incubated for each experiment.

Investigating the influence of controllable conditions on the AR80 activity

The controllable condition assessed was the nitrogen source available to the AR80. The abilities of yeast extract, urea, and ammonium nitrate to act as nitrogen sources were assessed, and they were added to the medium at concentrations of $0.100,0.025$, and $0.030 \mathrm{~g} / \mathrm{L}$, respectively, to give the same nitrogen concentration in each test medium. AR80 was also incubated in the culture medium without a nitrogen source as a control. The optimum concentration of the most suitable nitrogen source was assessed by performing incubation experiments with culture media containing different concentrations of that nitrogen source.

Investigating the influence of uncontrollable conditions on the AR80 activity

The influence of temperature on the AR80 activity was assessed. AR80 was incubated in the culture medium (containing the optimum concentration of the chosen nitrogen source) at $50,60,70$, and $80{ }^{\circ} \mathrm{C}$. The influence of salinity on the AR80 activity was assessed in incubation experiments using the medium containing the optimum concentration of the chosen nitrogen source with 10,30,60, and $90 \mathrm{~g} / \mathrm{L}$ of $\mathrm{NaCl}$ present. The influence of pressure on the AR80 activity was assessed in incubation experiments using the medium containing the optimum concentration of the chosen nitrogen source in high-pressure cylinders at $6.0 \mathrm{MPa}$ and $60{ }^{\circ} \mathrm{C}$. The pressure was increased by injecting $10 \% \mathrm{CO}_{2}$ into the cylinders at $0.2 \mathrm{MPa}$ and then injecting pure $\mathrm{N}_{2}$ into the cylinders to reach 6.0 MPa.

Analytical methods

Culture solution $(100 \mu \mathrm{L})$ was extracted from each bottle every few days during the incubation experiments, and the growth of AR80 was determined by direct cell counting in a 0.02-mm deep bacteria chamber (Sunlead Glass Corp., Koshigaya, Japan) under phase contrast microscopy (BH-2; OLYMPUS Corp., Tokyo, Japan).

The crude oil was extracted into benzene $(5 \mathrm{~mL})$ that was placed into each bottle every few days during the incubation experiments. The benzene was completely evaporated from the extracted solution at $50{ }^{\circ} \mathrm{C}$. The viscosity of the extracted crude oil was measured using a rotational viscometer (Programmable Rheometer DV-III; Brookfield Eng., Middleboro, MA, USA) at $50{ }^{\circ} \mathrm{C}$. The crude oil was also analyzed by gas chromatography (GC) with a flame ionization detector (FID) (PU 4600; Philips, Eindhoven, the Netherlands) and the ratio of lighter to heavier $n$-alkanes components in the crude oil was estimated. A DB-1 chromatography column (Agilent J\&W, Santa Clara, CA, USA) was used for the analysis, and the carrier gas was nitrogen, used at a flow rate of $2.5 \mathrm{~mL} / \mathrm{min}$. The oven temperature was increased from 60 to $280{ }^{\circ} \mathrm{C}$ at a rate of $10{ }^{\circ} \mathrm{C} / \mathrm{min}$ and kept at the final temperature for $27 \mathrm{~min}$. The extracted crude oil was diluted with n-hexane 
and injected into the column using splitless injection mode. Each hydrocarbon component separated was detected by FID. Pure $n$-alkanes with carbon numbers of 10-32 were used as standards. The relative abundance of each $n$-alkane in the crude oil was calculated using Eq. 1.

$R_{i}=\frac{A_{i}}{\sum A_{i}}$,

where $R_{i}$ is the relative abundance of an $n$-alkane with a carbon number of $i$ and $A_{i}$ is the peak area of that $n$-alkane. The data presented are the means of the results from triplicate culture bottle tests and the analyses were repeated at least twice.

Core flooding experiment procedure

Duplicate core flooding experiments were performed with microbial treatment (T1 and $\mathrm{T} 2$ ) and without microbial treatment (NT1 and NT2). A schematic of the experimental setup used for the core flooding experiments is shown in Fig. 2. The properties of the Berea sandstone cores that were used in the study are shown in Table 2 . The cores were $70.0 \mathrm{~mm}$ long and $38.1 \mathrm{~mm}$ wide. The absolute permeability of each core was 300 millidarcy. The cores were sterilized at $180{ }^{\circ} \mathrm{C}$ for $6 \mathrm{~h}$. Each core was then vacuum saturated with filter-sterilized brine to determine its porosity and water wettability. The porosity of each core was found to be approximately $20.5 \%$. The brine-saturated cores were installed into Hassler-type core holders and 1.0 MPa radial confining pressure was introduced using pure nitrogen. Then, 3.5 pore volume (PV) of culture medium containing $1.0 \times 10^{6}$ cells $/ \mathrm{mL}$ AR80 was injected into cores $\mathrm{T} 1$ and $\mathrm{T} 2$ anaerobically, at a constant pressure of $0.02 \mathrm{MPa}$, to achieve a high concentration of bacteria spread through the rock pores. Similarly, 3.5 PV of sterile culture medium was injected into cores of NT1 and NT2 at the same injection pressure. The culture medium was natural brine supplemented with the nitrogen source chosen from the results of the incubation experiments. The culture medium was injected into the cores under pressure provided by applying $10 \% \mathrm{CO}_{2}$ in nitrogen. Crude oil that had been sterilized (in an autoclave) was then injected into the cores at a similar injection pressure until no more brine flowed out. Approximately $6.0 \mathrm{~mL}$ of water effluent was collected from each core during the crude oil injection process, so the original oil in place (OOIP) volume and the initial oil saturation were approximately $6.0 \mathrm{~mL}$ and $36.6 \%$, respectively.
Fig. 2 Schematic image of the experimental setup for the core flooding experiments

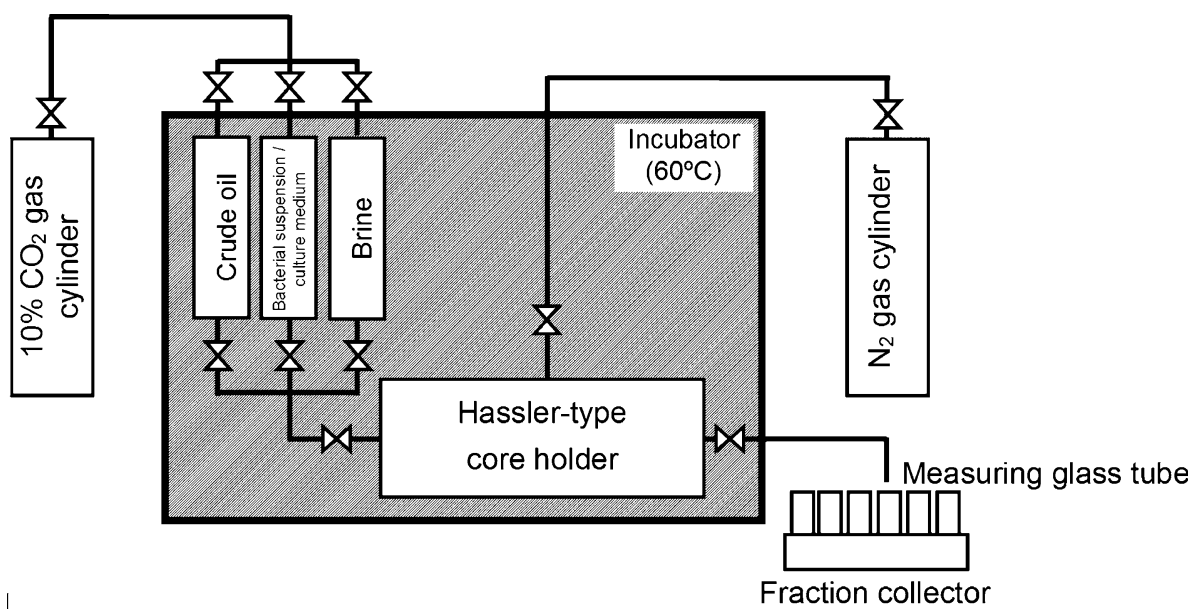

Table 2 Properties of the Berea sandstone cores before the treatments

\begin{tabular}{lllll}
\hline \multicolumn{4}{l}{ Experimental number } & \\
\cline { 2 - 4 } & $\mathrm{T} 1$ & $\mathrm{~T} 2$ & $\mathrm{NT} 1$ & $\mathrm{NT} 2$ \\
\hline Treatment & \multicolumn{2}{l}{ Treated with AR80 } & Non-microbial treatment (Control) \\
Core length $(\mathrm{mm})$ & 70.0 & & \\
Core diameter $(\mathrm{mm})$ & 3.81 & & & 16.55 \\
Pore volume $(\mathrm{mL})$ & 16.48 & 16.31 & 16.26 & 20.73 \\
Porosity $(\%)$ & 20.65 & 20.44 & 20.37 & \\
Absolute permeability $(\mathrm{mD})$ & 300 & & & 5.75 \\
Oil viscosity at $60{ }^{\circ} \mathrm{C}(\mathrm{cP})$ & 7.0 & & & 34.75 \\
Original oil in place $(\mathrm{mL})$ & 6.37 & 6.10 & 5.78 & \\
Initial oil saturation $(\%)$ & 38.65 & 37.40 & 35.55 & \\
\hline
\end{tabular}


The culture medium containing $1.0 \times 10^{6}$ cells $/ \mathrm{mL}$ of AR80 was again injected into cores T1 and T2 at the same injection pressure until no more oil was observed in the effluent. Similarly, the sterile culture medium was injected into cores NT1 and NT2. The effluent was collected into glass measuring tubes at specific time intervals, and the amount of effluent oil and water was determined volumetrically. At this stage of the experiment, the crude oil in the water effluent was called 'primary oil recovery'. All of the core holders (for both the bacterial treatments and the controls) were then closed and incubated at $60{ }^{\circ} \mathrm{C}$ for 2 weeks, then 3.5 PV of filter-sterilized brine was injected into each core at the same injection pressure. The effluent was collected into glass measuring tubes at specific time intervals. The crude oil obtained during this stage was called 'secondary oil recovery'. The bacterial cell numbers in the effluent collected during the secondary recovery were counted by phase contrast microscopy. The primary oil recovery and secondary oil recovery crude oil samples were analyzed by GC-FID.

\section{Results}

Influence of controllable conditions on the AR80 activity

\section{Type of nitrogen source}

Figure 3 shows the AR80 growth curves in the culture media supplemented with yeast extract, ammonium nitrate, and urea. AR80 grew well in all of the culture media, but particularly well in the culture medium supplemented with yeast extract. The AR80 growth rates in the culture media supplemented with yeast extract, ammonium nitrate, and urea were $0.154,0.149$, and $0.055 \mathrm{~h}^{-1}$, respectively. Figure 4 shows the decreases in oil viscosity in the culture media supplemented with yeast extract, ammonium nitrate, and urea. The highest decrease in oil viscosity was found in the culture medium supplemented with yeast extract. The oil viscosity decreased from 26.6 to $16.6 \mathrm{cP}$ after 2 weeks of incubation with AR80 and yeast extract, whereas it only decreased to 17.2 and $19.5 \mathrm{cP}$ with ammonium nitrate and urea, respectively. Figure 5 shows a chromatogram of crude oil that had been treated with AR80 in the medium supplemented with yeast extract for 2 weeks. For comparison, a chromatogram of the crude oil in a control sample is also shown. Almost all of the $n$-alkanes in the treated crude oil were degraded slightly, suggesting that AR80 simultaneously degraded a broad range of $n$-alkanes in the crude oil. Figure 6 shows the $n$-alkane composition ratio in the crude oil that had been treated for 2 weeks under the four different test conditions. The $\mathrm{C} 26-\mathrm{C} 30$ fraction was lower

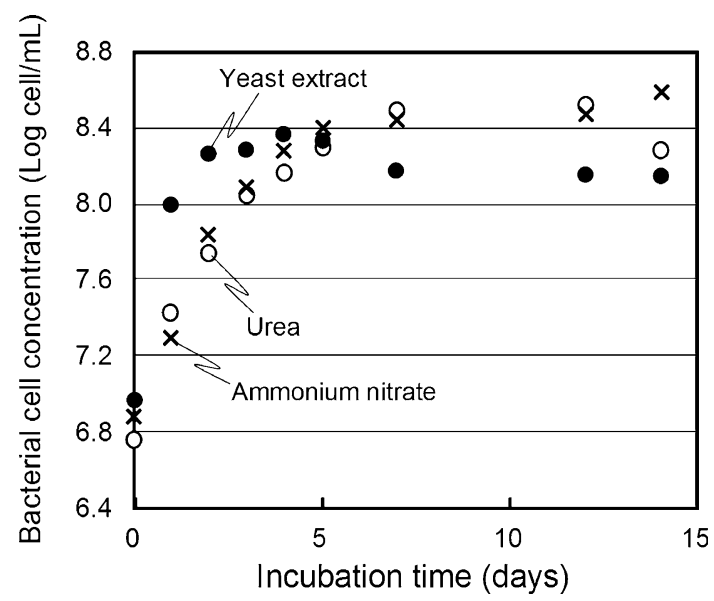

Fig. 3 AR80 growth curves with different nitrogen sources

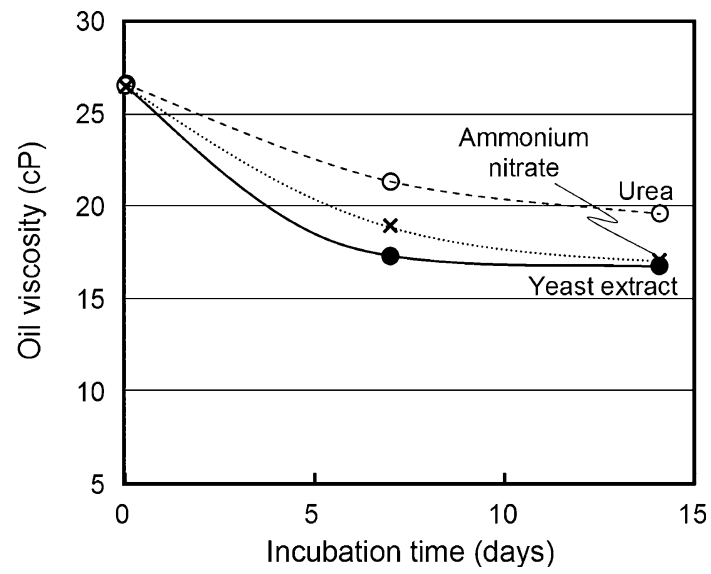

Fig. 4 Viscosity of oil treated with AR80 with different nitrogen sources

in all of the treated samples than in the controls. The C16C20 fraction was also lower in the treatments supplemented with yeast extract and urea than in the controls. In contrast, the short-chain $n$-alkane (such as the $\mathrm{C} 10-\mathrm{C} 15$ ) fractions were higher in the treatments supplemented with yeast extract and urea than in the controls.

These results show that yeast extract is the most suitable nitrogen source for stimulating AR80 activity, so yeast extract was used as the nitrogen source in the subsequent experiments.

\section{Yeast extract concentration}

AR80 was incubated in culture media containing 0.05 , $0.10,0.20$, and $0.50 \mathrm{~g} / \mathrm{L}$ of yeast extract, and the AR80 growth curves are shown in Fig. 7. The AR80 growth rate increased as the yeast extract concentration increased. The growth rate was $0.92 \mathrm{~h}^{-1}$ at the highest yeast extract concentration, and $0.81,0.76$, and $0.71 \mathrm{~h}^{-1}$ at yeast extract concentrations of $0.20,0.10$, and $0.05 \mathrm{~g} / \mathrm{L}$, respectively. 
Fig. 5 Chromatograms of crude oil treated with a uninoculated blank and b AR80 in the culture medium

supplemented with yeast extract

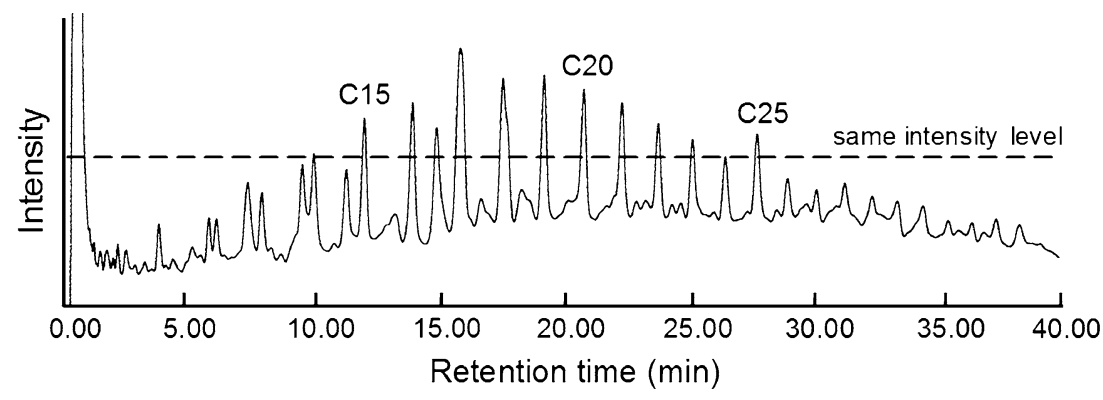

(a) Un-inoculated blank

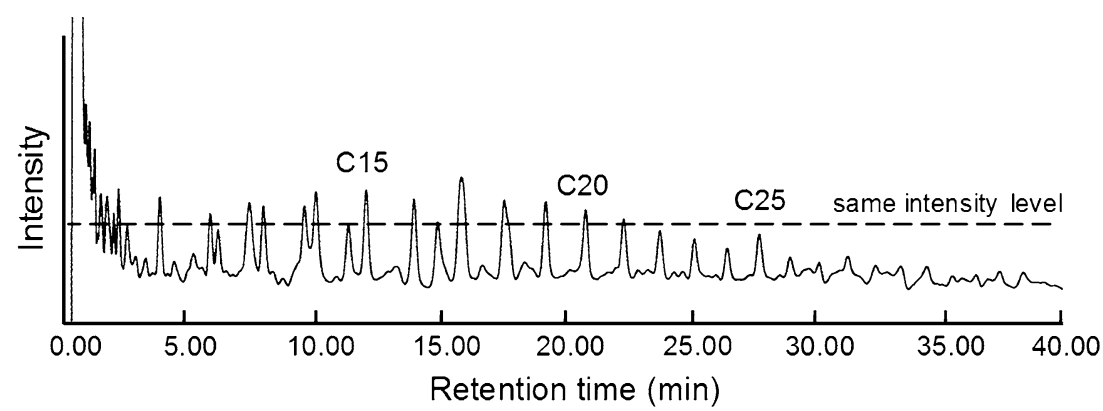

(b) Treated with AR80 in the culture medium supplemented with yeast extract

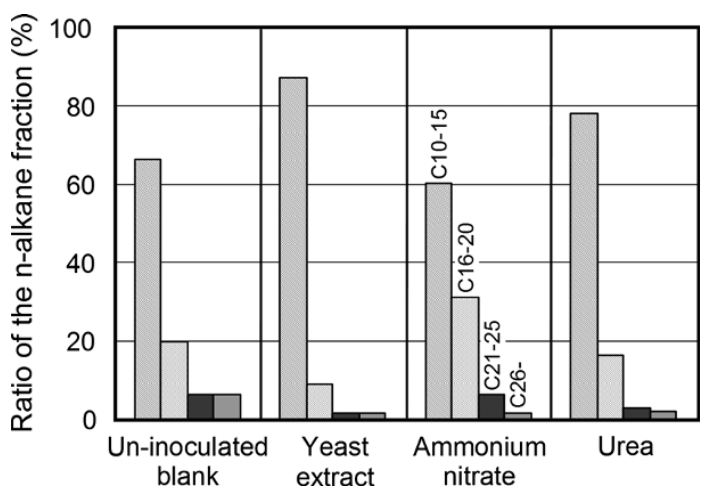

Fig. 6 Comparison of the $n$-alkane fractions in the oil treated using different nitrogen sources

Although the growth rate was different for the different treatments, the bacterial cell number increased during the incubation period, to $2.0-3.0 \times 10^{8}$ cells $/ \mathrm{mL}$, in all of the treatments. The decrease in the oil viscosity was also similar for each treatment (data not shown). In the subsequent experiments, $0.05 \mathrm{~g} / \mathrm{L}$ of yeast extract was used.

Influence of uncontrollable conditions on the AR80 activity

\section{Temperature}

Growth curves for AR80 incubated at different temperatures are shown in Fig. 8. The AR80 growth rate decreased

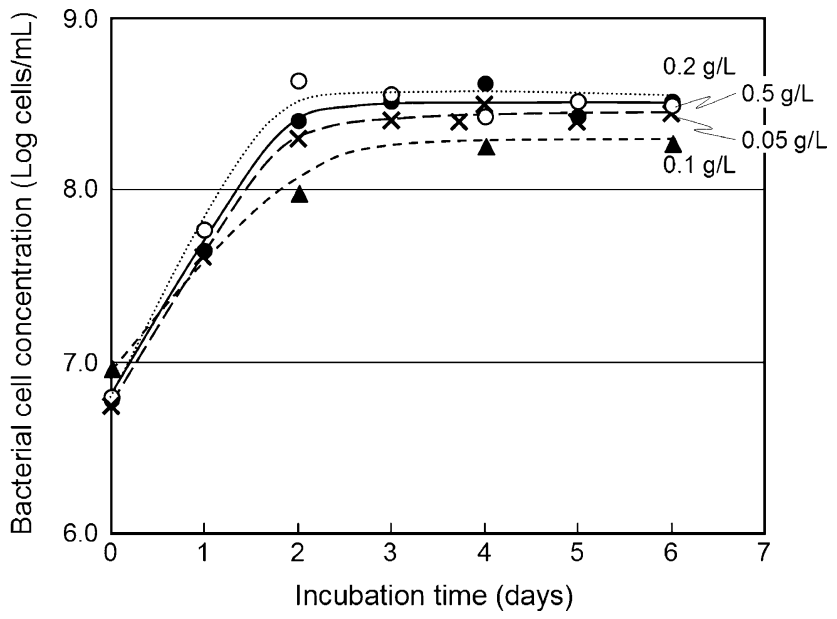

Fig. 7 Growth curves for AR80 incubated with different yeast extract concentrations

with increasing temperature. The growth rates were 0.66 , $0.48,0.25$, and $0.15 \mathrm{~h}^{-1}$ at $50,60,70$, and $80{ }^{\circ} \mathrm{C}$, respectively.

The viscosity of the crude oil increased in the control samples that had been incubated at above $60{ }^{\circ} \mathrm{C}$, and this was caused by the light components in the crude oil evaporating at such high temperatures. Therefore, we estimated the decrease in the oil viscosity as the relative viscosity, that is, relative to the viscosity of the oil in the corresponding control sample. Figure 9 shows the relative viscosities of the oil after it had been treated with AR80 at 


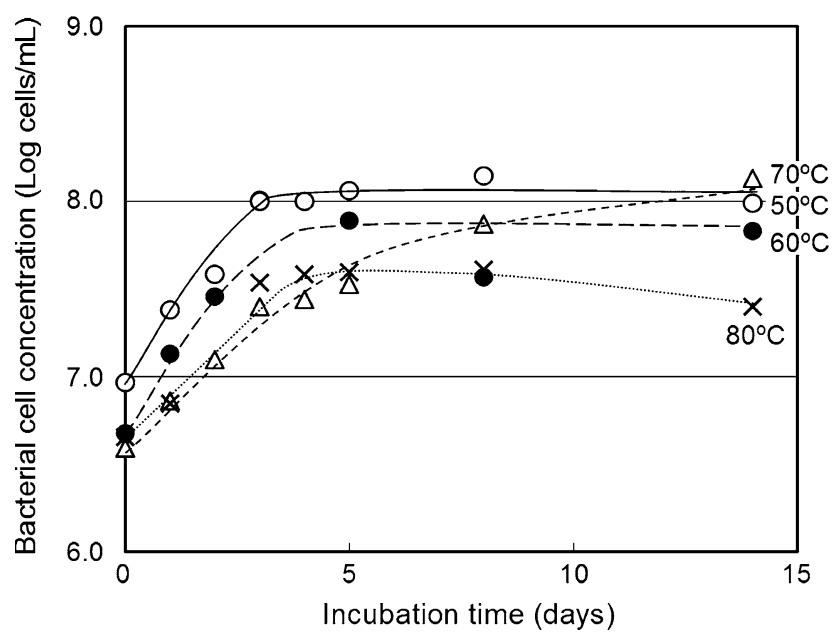

Fig. 8 Growth curves for AR80 incubated at different temperatures

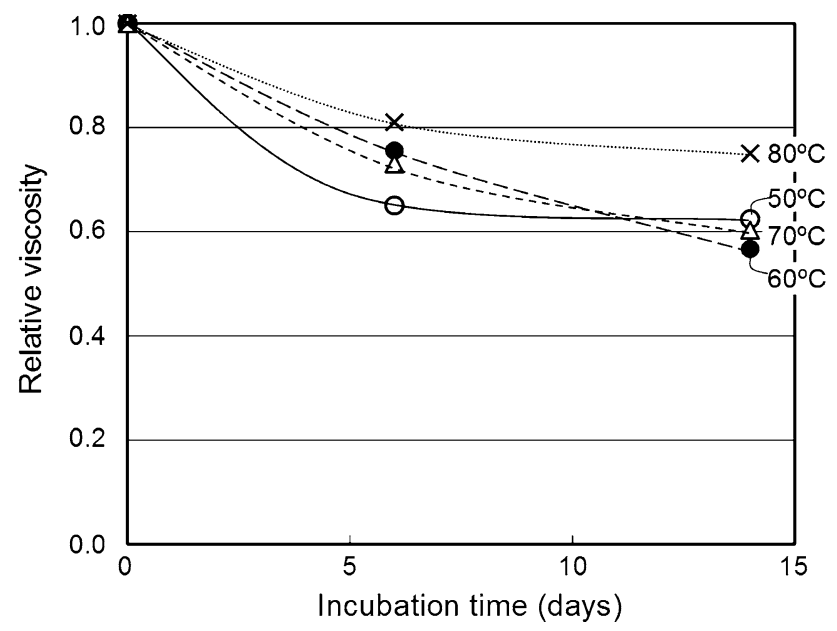

Fig. 9 Viscosity of oil treated with AR80 at different temperatures

$50,60,70$, and $80^{\circ} \mathrm{C}$. The relative viscosity decreased to $0.62,0.57,0.60$, and 0.75 after 2 weeks of incubation with AR80 at 50,60, 70, and $80^{\circ} \mathrm{C}$, respectively.

\section{Salinity}

Figure 10 shows the AR80 growth curves at different salinities. AR80 was able to grow at each salinity that was tested, but its growth rate and maximum number of cells decreased as the salinity increased. The specific growth rate of AR80 was $0.66 \mathrm{~h}^{-1}$ at a salinity of $10 \mathrm{~g} / \mathrm{L}$, which was original salinity of the brine, and $0.49,0.31$, and $0.22 \mathrm{~h}^{-1}$ at salinities of 30,60 , and $90 \mathrm{~g} / \mathrm{L}$, respectively. The bacterial cell numbers reached $2.0 \times 10^{8}, 1.5 \times 10^{8}$, $5.0 \times 10^{7}$, and $2.5 \times 10^{7}$ cells $/ \mathrm{mL}$ at salinities of 10,30 , 60 , and $90 \mathrm{~g} / \mathrm{L}$, respectively. The oil viscosity could not be measured accurately in this experiment because the oil formed a mousse with the highly saline media during the

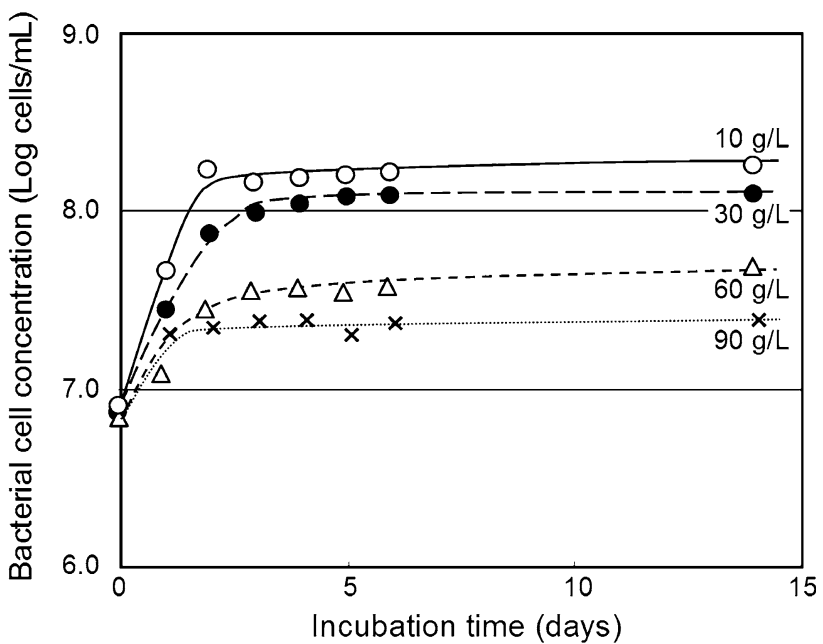

Fig. 10 Growth curves for AR80 incubated at different salinities

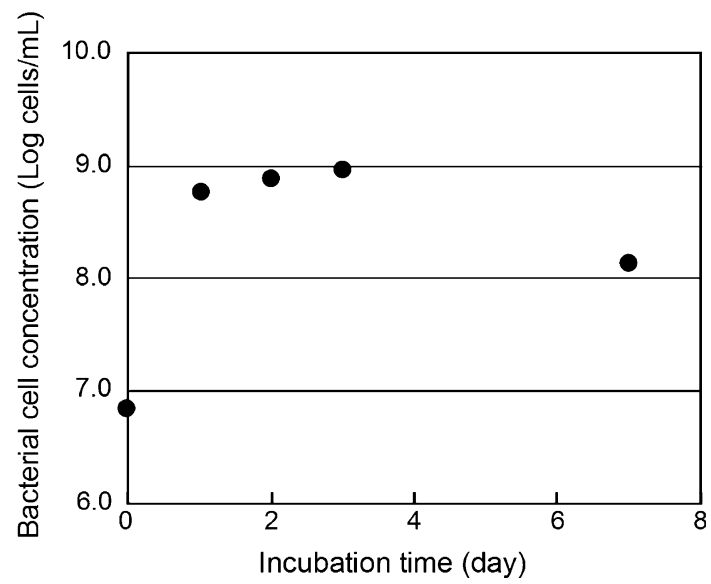

Fig. 11 Growth curve for AR80 incubated at 6.0 MPa

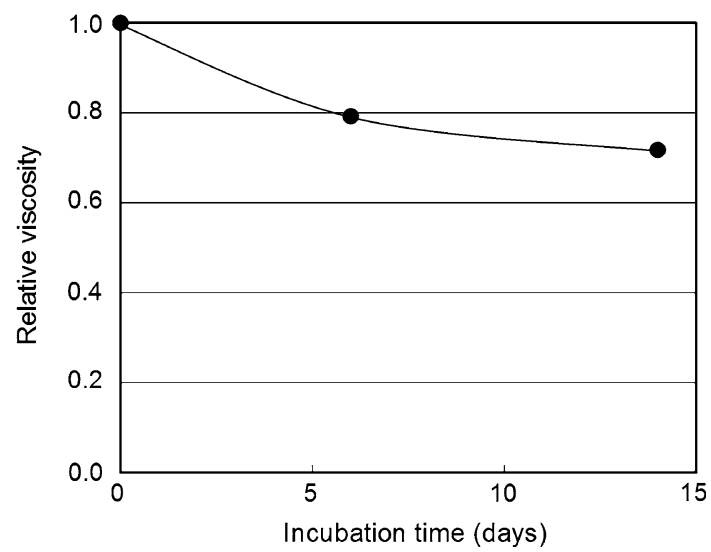

Fig. 12 Viscosity of oil treated with AR80 at $6.0 \mathrm{MPa}$

incubation period. The decrease in oil viscosity can be expected to have become smaller as the salinity increased based on the AR80 growth results at each salinity condition described above. 


\section{Pressure}

Figure 11 shows the growth curve of AR80 incubated at 6.0 MPa and $60{ }^{\circ} \mathrm{C}$. The AR80 had a specific growth rate of $0.65 \mathrm{~h}^{-1}$ and the number of cells increased to $1.0 \times 10^{9}$ cells $/ \mathrm{mL}$, which was the highest number of cells achieved in this study. Figure 12 shows the changes in the relative viscosity of the oil during the incubation period. The relative viscosity decreased to 0.65 after a 2-week incubation period.

\section{Core flooding experiments}

AR80 started to be detected in the effluent brine once 0.3 PV of the microbial suspension had been injected. The number of AR80 cells in the effluent became relatively constant, at around $6.5 \times 10^{5}$ cells/mL (35\% less than the original bacterial suspension concentration), once $0.7 \mathrm{PV}$ of the microbial suspension had been injected.

Figure 13 shows the cumulative oil recovery from each experiment. There was little difference in the cumulative oil recovery between the experiments, with 49.9, 41.6, 39.6, and $41.7 \%$ of the OOIP being recovered in the T1, T2, NT1, and NT2 experiments, respectively, as primary oil recovery. The injected bacterial suspension broke through the core later in experiment $\mathrm{T} 1$ than in the other experiments because the flow velocity was lower in experiment $\mathrm{T} 1$ than in the other experiments. Therefore, the primary oil recovery was higher in experiment $\mathrm{T} 1$ than in the other experiments. A negligible amount of crude oil was drained from the core in the early stages of secondary oil recovery. The drainage of the remaining oil started to be clearly detected after 0.2-0.4 PV of brine had been injected in both of the microbial treatment experiment cores, while the remaining oil was not found to

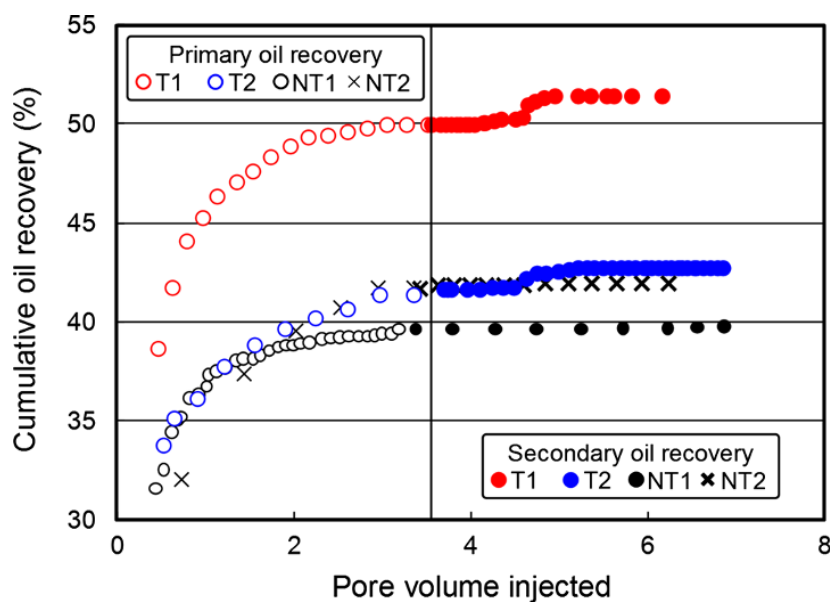

Fig. 13 Cumulative oil recovery in each core flooding experiment
Table 3 Results of the core flooding experiments

\begin{tabular}{|c|c|c|c|c|}
\hline & \multicolumn{4}{|c|}{ Experimental number } \\
\hline & $\mathrm{T} 1$ & $\mathrm{~T} 2$ & NT1 & NT2 \\
\hline $\begin{array}{l}\text { Pore volume of injected culture medium } \\
\text { in the primary oil recovery }\end{array}$ & 3.90 & 3.74 & 3.18 & 3.35 \\
\hline Primary oil recovery $(\%)$ & 49.92 & 41.64 & 39.62 & 41.70 \\
\hline $\begin{array}{l}\text { Residual oil saturation after the primary } \\
\text { oil recovery }(\%)\end{array}$ & 19.35 & 21.83 & 21.46 & 20.26 \\
\hline Pore volume of injected culture medium & \multicolumn{2}{|c|}{$\begin{array}{l}3.0 \text { (with } \\
\text { AR80) }\end{array}$} & \multicolumn{2}{|c|}{$\begin{array}{l}3.0 \text { (without } \\
\text { AR80) }\end{array}$} \\
\hline Shut-in time (days) & \multicolumn{4}{|l|}{14} \\
\hline $\begin{array}{l}\text { Pore volume of injected brine in the } \\
\text { secondary oil recovery }\end{array}$ & 2.60 & 3.16 & 4.08 & 2.99 \\
\hline Secondary oil recovery vs. OOIP (\%) & 1.46 & 1.21 & 0.29 & 0.33 \\
\hline $\begin{array}{l}\text { Secondary oil recovery vs. residual oil } \\
(\%)\end{array}$ & 2.92 & 2.90 & 0.49 & 0.57 \\
\hline
\end{tabular}

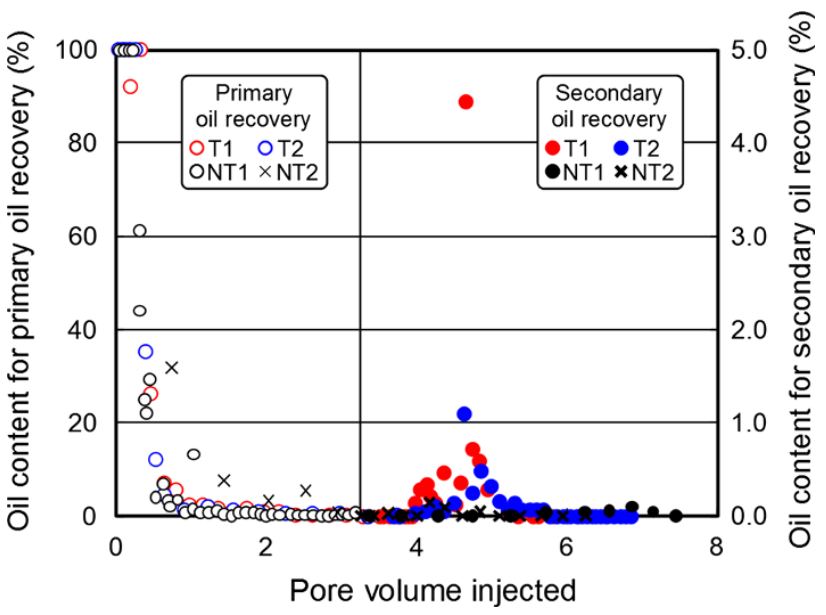

Fig. 14 Oil content in the effluent from each core flooding experiment

drain in either of the control experiments. Drainage of the remaining oil was observed until $1.5 \mathrm{PV}$ of brine had been injected in both of the microbial treatment experiments. The final oil recovery in experiments $\mathrm{T} 1$ and $\mathrm{T} 2$ reached 51.4 and $42.8 \%$, respectively, i.e., 1.5 and $1.2 \%$ of the OOIP had been drained from the cores because of the microbial treatments (Table 3).

The changes in the oil content in the effluent from each experiment are shown in Fig. 14. The oil content decreased sharply once $0.2-0.4 \mathrm{PV}$ of brine had been injected, and oil drainage was not observed after 3.0 PV of brine had been injected during the primary oil recovery. The oil content started to increase once $0.2-0.4$ PV of brine had been injected in both of the microbial treatment experiments, as described above, during secondary oil recovery. Maximum 
Fig. 15 Chromatograms of crude oil treated with a nonmicrobial control (NT1) and b AR80 (T1)

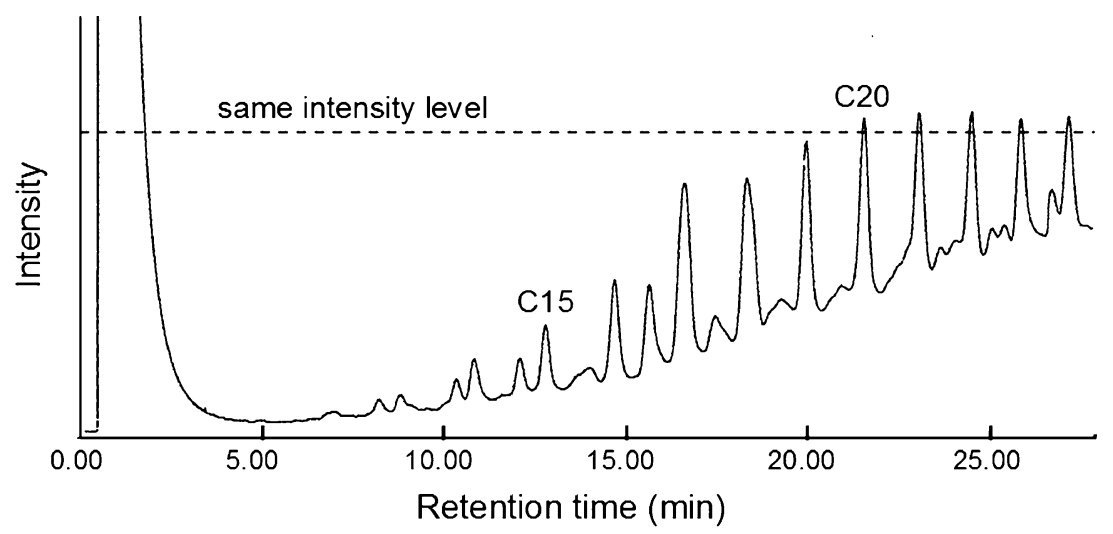

(a) Non-microbial treatment (NT1)

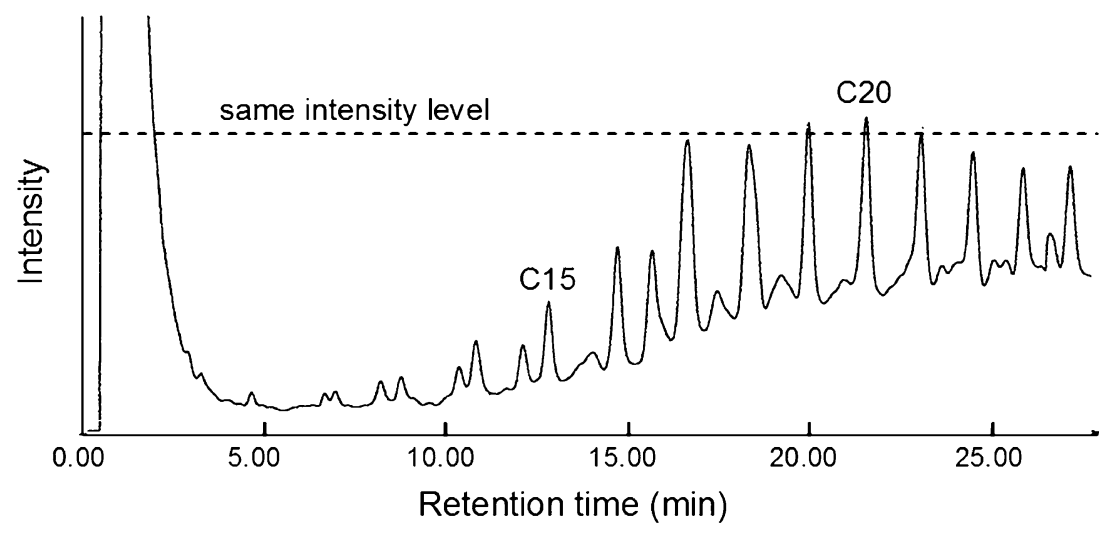

(b) Treated with AR80 (T1) oil contents of 4.4 and $1.1 \%$ were observed once $1.1 \mathrm{PV}$ of brine had been injected in experiments $\mathrm{T} 1$ and $\mathrm{T} 2$, respectively. Drainage of the remaining oil finished once 1.5-2.0 PV of brine had been injected.

The number of AR80 cells in the effluent that flowed from the microbial-treated cores was observed when between 0.2 and $0.3 \mathrm{PV}$ of brine had been injected. The numbers of AR80 cells in the $\mathrm{T} 1$ and $\mathrm{T} 2$ effluents were $1.4 \times 10^{7}$ and $1.8 \times 10^{7}$ cells $/ \mathrm{mL}$, respectively. Fluorescence microscopy revealed that AR80 cells remained in the cores after the secondary oil recovery (data not shown). The effluent oil chromatograms for experiments T1 and NT1 are shown in Fig. 15. The $\mathrm{C} 20$ and lower $n$-alkane fractions were found at higher proportions in the cores treated with AR80 than in the controls, while the $\mathrm{C} 21$ and higher $n$-alkane fractions were found at lower proportions in the cores treated with AR80 than in the controls. Although the viscosity of the effluent oil could not be measured because enough oil to make the measurements could not be recovered in the experiments, a decrease in the oil viscosity in the cores could be expected based on the GC analysis results.

\section{Discussion}

Mechanisms involved in AR80 causing the oil viscosity to decrease

AR80 can degrade long-chain $n$-alkanes preferentially, increasing the ratio between the short-chain and long-chain $n$-alkane concentrations in crude oil. Metabolism by AR80 caused the decrease in oil viscosity described above. Although a large number of microorganisms, with a wide range of physiological properties, have been isolated from oil reservoirs, only a very small number of anaerobic thermophilic oil-degrading bacteria have been reported. Rueter et al. (1994) identified only one anaerobic thermophilic oil-degrading bacterium that was potentially capable of inhabiting deep reservoirs. That was a sulfate-reducing bacterium that generated hydrogen sulfide when it degraded hydrocarbons, so it should not be used in MEOR to avoid reservoir souring. AR80 can degrade crude oil without generating hydrogen sulfide, so it is a candidate for use in MEOR. 
Supplementary nutrition for AR80 activity

The highest AR80 growth rates, and the highest numbers of cells, were found in the culture medium supplemented with yeast extract. Similarly, the greatest decrease in oil viscosity was found in the culture medium supplemented with yeast extract. Yeast extract contains many amino acids, which bacteria can take up easily, so the AR80 activity was stimulated in the culture medium supplemented with yeast extract. The yeast extract concentration had little or no effect on the maximum number of AR80 cells or the decrease in oil viscosity. From the standpoint of costs for MEOR operations, $0.05 \mathrm{~g} / \mathrm{L}$ yeast extract is necessary and is sufficient to stimulate AR80 activity. Yeast extract for food industry use is not very expensive, at US\$1-10/ton, although the cost of high-quality yeast extract for research use (used in this study) is more than US\$300/ $\mathrm{kg}$. If AR80 activity can also be stimulated by yeast extract intended for food industry use, MEOR using AR80 could be performed without impairing its economic advantage.

\section{Screening criteria for MEOR using AR80}

AR80 grew at all of the temperatures tested, although the growth rate decreased as the temperature increased. Although the AR80 growth rate was lower at $70{ }^{\circ} \mathrm{C}$ than at 50 or $60{ }^{\circ} \mathrm{C}$, the number of bacterial cells reached the same level at $70{ }^{\circ} \mathrm{C}$ as at 50 or $60{ }^{\circ} \mathrm{C}$ after 2 weeks of incubation. As a result, the decrease in the relative viscosity was almost the same for the oil samples treated at 50,60, and $70{ }^{\circ} \mathrm{C}$ after 2 weeks of incubation. The relative viscosity was also decreased even at $80{ }^{\circ} \mathrm{C}$, although it was higher at that temperature than at the other temperatures. The most suitable reservoir temperature for MEOR using AR80 is, therefore, $50-70{ }^{\circ} \mathrm{C}$, but AR80 can be used in reservoirs with temperatures below $80^{\circ} \mathrm{C}$. Although AR80 grew even at a high salinity (e.g., $90 \mathrm{~g} / \mathrm{L}$ ), the growth rate became lower as the salinity increased. The most suitable reservoir salinity for MEOR using AR80 is $<30 \mathrm{~g} / \mathrm{L}$, but AR80 can be used in reservoirs with a salinity below $90 \mathrm{~g} / \mathrm{L}$. Although the AR80 growth improved, the decrease in oil viscosity became smaller at higher pressures, such as 6.0 MPa. This result agrees with that reported by Atlas (1981), who showed that $94 \%$ of hexadecane was used by bacteria within 8 weeks at 1 bar but that it took 40 weeks to achieve a similar degradation level by the same bacteria at 500 bars. It appears that the rate of hydrocarbon degradation by AR80 is lower at high pressures than at ordinary pressures. However, the relative viscosity of the oil decreased to 0.72 after a 2-week incubation period at high pressure, so the AR80 activity will not be seriously affected by higher reservoir pressures.
Mechanisms involved in oil recovery during MEOR using AR80

Some of the injected AR80 remained in the porous rocks during the injection of the bacterial suspension, which might be caused by their adsorption onto the rock surface and/or their clogging of the pore space. However, adsorption and clogging were assumed not to affect the injectivity of AR80 because the effluent rate remained relatively constant throughout the injection (data not shown). AR80 can be used in MEOR from the viewpoint of its ability to flow through porous rocks.

More than $10^{7}$ cells $/ \mathrm{mL}$ of AR80 were found in the effluent sampled during secondary oil recovery, suggesting that AR80 increased more than tenfold in the cores during the incubation period. Assuming that some of the AR80 remained in the cores, AR80 could be expected to increase to higher cell numbers within the rock than were observed in the effluent brine. These results suggest that AR80 can grow actively in porous rocks.

The bacterial cell concentration was $35 \%$ lower in the effluent brine than it was in the original bacterial suspension because of the adsorption of bacterial cells onto the sandstone surface, as described above. There is also a possibility that some components of the culture medium adsorbed onto the sandstone surface. For these reasons, we assumed that there were bacterial concentration and/or nutrient concentration gradients in the cores after the primary oil recovery stage, and that their concentrations would have been higher in the upstream parts of the cores than in the downstream parts of the cores. As a result, the remaining oil in the upstream parts of the cores would have been actively degraded by AR80, and its viscosity would have become lower in the upstream than in the downstream parts of the cores. This would have led to a delay in finding enhanced oil recoveries during the secondary oil recovery stage (in Figs. 13, 14) relative to the average decrease in the oil viscosity in the core.

A decrease in the viscosity of oil treated with AR80 in the cores can be expected because an increase in the ratio between the short-chain $n$-alkane and long-chain $n$-alkane concentrations was found in the effluent oil, as described above. The decrease in viscosity would have improved the oil-water mobility ratio and the water sweep efficiency during secondary oil recovery. The brine injected during secondary oil recovery would, therefore, have flowed into regions that had not been flooded by brine during primary oil recovery. The remaining oil in those regions would have been displaced by the brine and an oil bank would have formed ahead of the slug of brine injected during secondary oil recovery. A high oil content fluid drained from the core when the oil bank reached the core outlet, as shown in Fig. 14. 
The production of effective bioproducts, such as surfactants, gases, or polymers, by AR80 was not observed in the incubation experiments using the culture medium, so the additional oil recovery appears to have solely been caused by the decrease in viscosity of the remaining oil by AR80.

\section{Conclusions}

We assessed the potential for using an anaerobic thermophilic bacterium named AR80, which we isolated from an oilfield, as a candidate for MEOR. We assessed the ability of AR80 to anaerobically degrade hydrocarbons in crude oil and decrease the crude oil viscosity in a number of incubation experiments. We assessed, from the MEOR standpoint, the influence of controllable conditions, such as the type of nutrient present and uncontrollable conditions, such as the temperature, salinity, and pressure, on the AR80 activity. We also performed core flooding experiments to evaluate the enhancement of oil recovery during MEOR that could be achieved using AR80. Our main findings are described below.

1. AR80 was characterized as an anaerobic hydrocarbondegrading microorganism, which could preferentially degrade long-chain $n$-alkanes in crude oil and improve the ratio between the short-chain and long-chain $n$ alkane concentrations in the crude oil. The viscosity of the crude oil was decreased by this selective degradation.

2. Yeast extract is the most suitable nitrogen source for AR80 activity. The oil viscosity was decreased to $60 \%$ of its original value after incubation with AR80 in the culture medium supplemented with yeast extract. From the standpoint of the cost of MEOR, $0.05 \mathrm{~g} / \mathrm{L}$ is a necessary and sufficient yeast extract concentration for stimulating AR80 activity.

3. The most suitable temperature for AR80 activity is 50-70 ${ }^{\circ} \mathrm{C}$, but AR80 can be used in reservoirs with temperatures below $80{ }^{\circ} \mathrm{C}$.

4. A salinity of below $30 \mathrm{~g} / \mathrm{L}$ is suitable for $\mathrm{AR} 80$ activity, but AR80 can be used in reservoirs with salinities below $90 \mathrm{~g} / \mathrm{L}$.

5. The AR80 activity is not be seriously affected by the reservoir pressure.

6. AR80 can be injected into and grow in porous rocks. AR80 can degrade long-chain $n$-alkanes preferentially and improve the ratio between the short-chain and long-chain $n$-alkane concentrations in crude oil in porous rocks.
7. AR80 activity enhanced the oil recovery from porous rocks in the core flooding experiments, so AR80 could be a good candidate for use in MEOR.

Acknowledgments This work was supported by JSPS KAKENHI Grant Number 21760678 and Kyushu University G-COE program Novel Carbon Resource Science. We gratefully acknowledge the INPEX Corporation in Japan for their support and cooperation in providing the brine sample. We are also grateful to Dr. Kazuhiro Fujiwara for his technical advice. We appreciate technical support for our anaerobic incubation experiments provided by the Research Support Center, Graduate School of Medical Sciences, Kyushu University.

Open Access This article is distributed under the terms of the Creative Commons Attribution License which permits any use, distribution, and reproduction in any medium, provided the original author(s) and the source are credited.

\section{References}

Atlas RM (1981) Microbial degradation of petroleum hydrocarbons: an environmental perspective. Microbiol Rev 45:180-209

Bass C, Lappin-Scott H (1997) The bad guys and the good guys in petroleum microbiology. Oilfield Rev 9:17-25

Dong-Hui H, Jian-Qun L, Xin S, Jian-Qiang L, Yu-Jie S, Yin-Bo Q (2008) Isolation, identification, and performance studies of a novel paraffin-degrading bacterium of Gordonia amicalis LH3. Biotechnol Bioproc Eng 13:61-68

Fujiwara K, Sugai Y, Chui J, Enomoto H (2008) Recent advances and prospects in microbial enhanced oil recovery (MEOR) - movement towards practical EOR technology. J Jpn Assoc Pet Technol 73:296-306

Hanaa AS, Sanket J, Yahya AW, Saif AB, Abdulkadir E, Ali AB (2011) Microbial biotechnology for enhancing oil recovery: current developments and future prospects. Biotechnol Bioinf Bioeng 1:147-158

Isty AP, Sugai Y, Sasaki K (2014) Utilization of natural reservoir brine in enrichment culture medium: an alternative approach for isolation of anaerobic bacteria from an oil reservoir. Pet Sci Technol (to be published)

Kotlar HK, Wetzel A, Thorne-Holst M, Zotchev S, Ellingensen T (2007) Wax control by biocatalytic degradation in high-paraffinic crude oils. SPE paper 106420, presented at the SPE international symposium on oilfield chemistry, Houston

Lazar I, Voicu A, Nicolescu C, Mucenica D, Dobrota S, Petrisor IG, Stefanescu M, Sandulescu L (1999) The use of naturally occurring selectively isolated bacteria for inhibiting paraffin deposition. J Pet Sci Eng 22:161-169

Miranda-Tello E, Fardeau M-L, Joulian C, Magot M, Thomas P, Tholozan J-L, Olliver B (2007) Petrotoga halophila sp. nov., a thermophilic, moderately halophilic, fermentative bacterium isolated from an offshore oil well in Congo. Int $\mathbf{J}$ Syst Evol Microbiol 57:40-44

Rueter P, Rabus R, Wilkes H, Aeckersberg F, Rainey FA, Jannasch HW, Widdel F (1994) Anaerobic oxidation of hydrocarbons in crude-oil by new types of sulfate-reducing bacteria. Nature 372:455-458

Sadeghazad A, Ghaemi N (2003) Microbial prevention of wax precipitation in crude oil by biodegradation mechanism. SPE

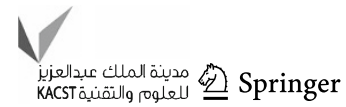


paper 80529, presented at the SPE asia pacific oil and gas conference and exhibition, Jakarta

Wang J, Ma T, Zhao L, Lv L, Li G, Zhang H, Zhao B, Liang F, Liu R (2008) Monitoring exogenous and indigenous bacteria by PCRDGGE technology during the process of microbial enhanced oil recovery. J Ind Microbiol Biotechnol 35:619-628

Wankui G, Chengfang S, Zhenyu Y, Zhaowei H, Rui J, Ying W, Jiyuan Z, Guoghao S (2006) Microbe-enhanced oil recovery technology obtains huge success in low-permeability reservoirs in Daqing oilfield. SPE paper 104281, presented at the SPE eastern regional meeting, Canton
Yijiang Z, Zhengshun X, Ping J, Weihong H (1999) Microbial EOR laboratory sudies and application results in Daqing oilfield. SPE paper 54332, presented at the SPE asia pacific oil and gas conference and exhibition, Jakarta

Youssef N, Elshahed MS, McInerney MJ (2009) Microbial process in oil fields: culprits, problems and opportunities. In: Allen IL, Sima S, Geoffrey MG (eds) Advances in applied microbiology. Academic press, Burlington, pp 141-251 